\title{
Serotonin Differentially Modulates Responses to Tones and Frequency-Modulated Sweeps in the Inferior Colliculus
}

\author{
Laura M. Hurley and George D. Pollak \\ University of Texas, Austin, Texas 78712
}

Although almost all auditory brainstem nuclei receive serotonergic innervation, little is known about its effects on auditory neurons. We address this question by evaluating the effects of serotonin on sound-evoked activity of neurons in the inferior colliculus (IC) of Mexican free-tailed bats. Two types of auditory stimuli were used: tone bursts at the neuron's best frequency and frequency-modulated (FM) sweeps with a variety of spectral and temporal structures. There were two main findings. First, serotonin changed tone-evoked responses in $66 \%$ of the IC neurons sampled. Second, the influence of serotonin often depended on the type of signal presented. Although serotonin depressed tone-evoked responses in most neurons, its effects on responses to FM sweeps were evenly mixed between depression and facilitation. Thus in most cells serotonin had a different effect on tone-evoked responses than it did on FMevoked responses. In some neurons serotonin depressed re- sponses evoked by tone bursts but left the responses to FM sweeps unchanged, whereas in others serotonin had little or no effect on responses to tone bursts but substantially facilitated responses to FM sweeps. In addition, serotonin could differentially affect responses to various FM sweeps that differed in temporal or spectral structure. Previous studies have revealed that the efficacy of the serotonergic innervation is partially modulated by sensory stimuli and by behavioral states. Thus our results suggest that the population activity evoked by a particular sound is not simply a consequence of the hard wiring that connects the IC to lower and higher regions but rather is highly dynamic because of the functional reconfigurations induced by serotonin and almost certainly other neuromodulators as well.

Key words: serotonin; inferior colliculus; auditory; neuromodulation; brainstem; frequency modulation
A major focus of auditory research has been on how acoustic information is encoded in the inferior colliculus (IC) (Yin and Kuwada, 1984; Aitkin, 1986; Pollak et al., 1986; Brugge, 1992; Irvine, 1992; Oliver and Huerta, 1992). The IC is of particular interest because it is a nexus in the ascending auditory pathway. It receives and integrates information coming from almost all lower auditory nuclei and as a consequence is involved in most, if not all, aspects of auditory processing (Beyerl, 1978; Roth et al., 1978; Adams, 1979; Brunso-Bechtold et al., 1981; Zook and Casseday, 1982; Aitkin, 1986; Ross et al., 1988; Oliver and Huerta, 1992; Vater et al., 1992).

The pathways ascending from lower regions, however, are not the only sources of innervation to the IC. Other sources include descending input from the cortex (Huffman and Henson, 1990) and from neuromodulatory networks that include serotonergic, cholinergic, dopaminergic, and noradrenergic systems (Olazábal and Moore, 1989; Henderson and Sherriff, 1991; Klepper and Herbert, 1991; Thompson et al., 1994; Kaiser and Covey, 1997). The innervation from the neuromodulatory systems is diffuse, in that a few neurons from each system innervate large numbers of neurons in each brain region. An example is serotonergic innervation, which originates from cell groups in the raphe of the brainstem. Serotonergic raphe neurons innervate virtually all regions of the CNS, from telencephalon to spinal cord, and these neurons play key roles in such diverse processes as development,

Received Feb. 12, 1999; revised June 18, 1999; accepted June 25, 1999.

This work was supported by National Institutes of Health Grant DC20068. We would like to thank Carl Resler for his technical support. We also thank Brad May, Paul Katz, Eric Bauer, Michael Burger, and Achim Klug for their critical comments.

Correspondence should be addressed to Dr. Laura Hurley, 140 Patterson, CO920, University of Texas, Austin, TX 78712.

Copyright (C) 1999 Society for Neuroscience 0270-6474/99/198071-12\$05.00/0 motor output, and sensory processing (e.g., Rogawski and Aghajanian, 1980; Bassant et al., 1990; Jacobs and Azmitia, 1992; Jankowska et al., 1994; Lavdas et al., 1997; Hsiao et al., 1998; Vitalis et al., 1998).

With regard to the auditory system, the serotonergic system is of particular interest because it innervates most, if not all, nuclei in the ascending auditory system (Willard et al., 1984; Klepper and Herbert, 1991; Thompson et al., 1994; Kaiser and Covey, 1997). However, the influence of serotonergic innervation on auditory processing is poorly understood, even though a great deal is known about serotonergic effects in a variety of nonauditory cells in both vertebrates and invertebrates (e.g., Rogawski and Aghajanian, 1980; Harris-Warrick et al., 1992; Oleskevich and Lacaille, 1992; Byrne and Kandel, 1996; Wang et al., 1996). Only three electrophysiological studies that evaluated the influence of serotonin have been conducted in brainstem auditory nuclei. One study by Ebert and Ostwald (1992) was conducted in the cochlear nucleus, and another study by Wang and Robertson (1997) was on the ventral nucleus of the trapezoid body and rostral periolivary zone. The descriptions in both studies are sparse and only report that serotonin can either facilitate or depress responses evoked by tone bursts or injected current. There is a comparable paucity of information about the influence of serotonin on IC neurons. The only information is contained in a short paragraph in a review of neurotransmitters in the IC by Faingold et al. (1991). There he briefly mentions that serotonin had only depressive effects on the six IC neurons that he studied.

To obtain additional insights into the functional roles that serotonin might have in the processing of acoustic information, we initiated studies to evaluate its effects on the responses of IC neurons evoked by simple and complex signals in Mexican free- 
tailed bats. We chose Mexican free-tailed bats as experimental subjects because they were the subjects of previous anatomical and physiological studies (Pollak et al., 1977; Bodenhamer et al., 1979; Grothe et al., 1994, 1997; Park et al., 1996, 1998). Those studies showed that their auditory nuclei are greatly hypertrophied but the circuitry and response properties of their brainstem auditory nuclei are fundamentally similar to those reported for other, less specialized mammals. Furthermore, these animals rely heavily on their sense of hearing for both communication and echolocation, and the features of many of those signals have been described (Simmons et al., 1978, 1979; Gelfand and McCracken, 1986; Balcombe and McCracken, 1992). Here we present the results from a study that evaluated the influence of serotonin on the responses evoked by both tone bursts and frequencymodulated (FM) signals whose structure approximates their echolocation calls. We show that serotonin has substantial effects on discharge properties of many IC neurons and that the particular effect often depends on the structure of the acoustic signal.

\section{MATERIALS AND METHODS}

Surgical procedures. Animals were anesthetized with methoxyflurane inhalation (Metofane; Mallinckrodt Veterinary, Mundelein, IL) and 0.02 $\mathrm{mg} / \mathrm{gm}$ neuroleptic Innovar-Vet (Pitman-Moore) injected intraperitoneally. The hair on the head was removed with a depilatory, and the head was placed in a holder with a bite bar. The skin and muscle overlying the skull were reflected after the topical application of $2 \%$ Lidocaine (Elkins-Sinn, Cherry Hill, NJ) to the initial incision. The surface of the skull was scraped free of tissue, and a foundation layer of cyanoacrylate and a layer of glass beads were applied to the skull. A small hole was then drilled over the center of the inferior colliculus.

The bat was transferred to a heated, sound-attenuated recording chamber, where it was placed in a restraining cushion constructed of foam molded to the animal's body. The restraining cushion was attached to a platform mounted on a custom-made stereotaxic instrument (Schuller et al., 1986). A small metal rod was cemented to the foundation layer on the skull and then attached to a bar mounted on the stereotaxic instrument to ensure a uniform positioning of the head. A ground electrode was placed between the reflected muscle and the skin. Recordings were begun after the bats recovered from the anesthetic. The bats typically lie quietly in the restraining cushion and show no signs of pain or discomfort. Water was provided with a dropper every 1-2 hr. Supplementary doses of the neuroleptic were given if the bat struggled or otherwise appeared in discomfort. If the bat continued to show signs of discomfort, recordings were terminated, and the bat was returned to its cage.

After the bat was placed in the recording chamber, the electrode was advanced to the surface of the IC through the previously drilled hole under a dissecting microscope. The electrode was subsequently advanced through the brain from outside of the recording chamber using a piezoelectric microdrive (model 6000; Burleigh, Fishers, NY). All experimental procedures were in accordance with a protocol approved by the University of Texas Institutional Animal Care and Use Committee.

Electrodes. Recordings were made with "piggy back" multibarrel electrodes (Havey and Caspary, 1980). A five-barrel H configuration blank (model 6120; A-M Systems, Carlsburg, WA) was pulled, and the tip was blunted to $10-15 \mu \mathrm{m}$. Recordings were made with a single-barrel micropipette, pulled previously, that was glued to the multibarrel array so that the tip of the recording electrode was $10-20 \mu \mathrm{m}$ from the blunted end of the multibarrel electrode. The recording electrodes had resistances of 8-15 $\mathrm{M} \Omega$. The recording electrodes and the central barrel of the multibarrel electrode were filled with buffered $1 \mathrm{M} \mathrm{NaCl}$ and $2 \%$ fast green, $\mathrm{pH}$ 7.4. The fast green allowed the electrodes to be easily visualized during placement over the inferior colliculus. The remaining barrels were each filled with serotonin creatinine sulfate $(20 \mathrm{~mm}$ in $200 \mathrm{~mm}$ $\mathrm{NaCl}, \mathrm{pH} 4)$ or the vehicle solution $(200 \mathrm{~mm} \mathrm{NaCl}$, pH 4). This concentration of serotonin was similar to that used previously by Faingold et al. (1991). Throughout the text we will also refer to serotonin as 5-hydroxytryptamine (5-HT). The barrels of the multibarrel electrode were connected via silver-silver chloride wires to a six-channel microiontophoresis constant-current generator (Neurophore, BH-2; Medical Systems, Greenvale, NY). The central barrel was connected to the sum channel to balance current in the drug barrels and reduce current effects on the recorded neuron. The recording electrode was connected via a silver-silver chloride wire to a Dagan AC amplifier (model 2400; Minneapolis, $\mathrm{MN}$ ). When a drug was not being applied, a retention current of $-15 \mathrm{nA}$ was applied to each drug barrel to prevent leakage. Drugs were applied by passing a positive ejection current that ranged from +10 to $+90 \mathrm{nA}$.

Acoustic stimulation, processing of spike trains, and iontophoresis. Search stimuli were tone bursts presented to the contralateral (excitatory) ear at a rate of 4 per second. The search tones were generated by a sine wave function generator (model 136; Wavetek, San Diego, CA) and shaped by a custom-made analog switch (model 15; Restek, Austin, TX). Tone bursts shaped by the switch were $10-20 \mathrm{msec}$ in duration and had 0.2 msec rise-fall times. Tone-burst frequency was monitored by a frequency counter. Tone bursts and downward-sweeping frequency-modulated (FM) signals having any desired duration as well as starting and terminal frequency could be digitally generated by the computer (Power Macintosh 7100/66). A 24-bit digital interface NuBus card (DIO-24; National Instruments, Austin, TX) and a digital distributor (model 99; Restek) communicated the Power Macintosh 7100/66 computer to a two-channel digital attenuator (model PATT; Wilsonics, San Jose, CA). The outputs of each independently controlled channel of the attenuator were sent to two $1 / 4$ inch Brüel \& Kjaer microphones biased with $200 \mathrm{~V} \mathrm{DC}$ and driven as loudspeakers. The loudspeakers were flat within $\pm 5 \mathrm{~dB}$ from 18 to at least $60 \mathrm{kHz}$. At the start of each experiment, speakers, with windscreens attached, were inserted into the funnels formed by the bat's pinnae and positioned adjacent to the external auditory meatus. The pinnae were folded onto the housing of the microphones and wrapped with Scotch tape. The acoustic isolation with this arrangement was at least $40 \mathrm{~dB}$.

Spikes were fed to a window discriminator and then to a Macintosh 7100 computer controlled by a Restek model 45 real-time clock. Peristimulus time (PST) histograms and rate-level functions were generated and graphically displayed. Unless otherwise noted, each PST histogram was generated from the discharges evoked by 20 presentations of a signal at a particular intensity.

After a unit was isolated, the best frequency (BF, the frequency to which the neuron was most sensitive) and the threshold at BF were determined. Threshold was defined as the intensity that evoked at least 4 spikes/20 tone bursts. After this initial evaluation of neuronal properties, computer-generated BF tone bursts and/or FM signals were presented to the contralateral ear. The tone bursts were either 10 or $20 \mathrm{msec}$ in duration and had $0.2 \mathrm{msec}$ rise-fall times. The FM signals had a duration of 5-10 msec with $0.2 \mathrm{msec}$ rise-fall times and had frequency excursions tailored to each neuron's BF. The FM signals always spanned $10 \mathrm{kHz}$ and swept downward from above the $\mathrm{BF}$ (usually $5 \mathrm{kHz}$ above) to beneath the $\mathrm{BF}$ (usually $5 \mathrm{kHz}$ beneath). Rate-level functions were obtained for each unit by plotting spike counts evoked by BF tone bursts or FM sweeps at intensities ranging from threshold, or 5-10 dB below threshold, to 40-50 $\mathrm{dB}$ above threshold in $10 \mathrm{~dB}$ increments. After the acquisition of these data, the same stimuli were presented during the application of serotonin. During serotonin application, rate-level functions were monitored while ejection currents from +10 to $+90 \mathrm{nA}$ were applied. For each ejection current, rate-level functions were obtained until spike counts had stabilized. After spike counts were stable, the complement of tone bursts or FM signals was presented again, and the same response features were obtained for comparison with those obtained before the application of drugs. The ejection current was then switched off, and "recovery" rate-level functions were obtained over the next 5-10 min.

Statistics. In addition to spike counts, we also measured latencies to first spikes and, where appropriate, interspike intervals. For individual neurons, ANOVAs were performed on latencies and interspike intervals, with sound intensity and treatment (pre-ejection or serotonin) as independent variables.

Pre-ejection and serotonin latencies were also compared across the population of inferior colliculus neurons. The latency value for each neuron was the average obtained from 20 sound presentations at each sound intensity. The latency values for each neuron were then normalized for threshold and pooled with values from other neurons. Preejection and serotonin values were then compared with paired two-tailed $t$ tests.

\section{RESULTS}

Here we report on the influence of 5-HT on 151 single cells from the inferior colliculi of Mexican free-tailed bats. All signals were 
presented monaurally to the contralateral ear. In 70 neurons we examined serotonin effects on the responses to tones, whereas in 45 neurons we evaluated effects of serotonin on the responses to standardized FM signals. These two groups of neurons overlapped by 35 neurons, in which we examined the effects of serotonin on responses to both tone bursts and FM sweeps in the same neuron. The term "standardized" refers to 5 or $10 \mathrm{msec}$ FM signals that swept downward through a $10 \mathrm{kHz}$ range and had a starting frequency that was usually $5 \mathrm{kHz}$ above the neuron's BF and a terminal frequency that was usually $5 \mathrm{kHz}$ below the BF. In 71 other neurons we evaluated the influence of serotonin on FM signals that had a variety of durations and sweep frequencies.

The principal effect of serotonin that we evaluated was whether it depressed or facilitated response magnitude. We considered that serotonin had either a depressive or facilitative effect if the spike counts evoked by either BF tone bursts or FM sweeps changed by at least $30 \%$ over the pre-ejection spike counts for at least one sound intensity. When changes in spike count occurred, they developed over the course of several minutes after serotonin was first applied and recovered either partially or completely within $5 \mathrm{~min}$ of terminating the application of serotonin. To ensure that whatever effects we observed were indeed caused by serotonin and not by the vehicle or by the iontophoretic current, we iontophoresed the vehicle alone in 39 neurons. In each neuron, we documented the cell's rate-level function before (pre-ejection) and during the iontophoresis of the vehicle. We then evaluated the effect of the vehicle by comparing the maximum tone-evoked spike counts before and during the ejection of the vehicle in each of the 39 neurons. Spike counts were measured at the lowest intensity that evoked the maximum response for neurons with monotonic rate-level functions and at 20-30 dB above threshold for neurons with nonmonotonic rate-level functions. In the preejection condition, the maximum tone-evoked response was, on average, $35.3 \pm 5.3$ spikes $( \pm \mathrm{SEM})$, whereas the same tones evoked an average spike count of $38.4 \pm 5.6$ spikes $( \pm$ SEM) while the vehicle solution was iontophoresed. The two values were not significantly different ( $p>0.05$, two-tailed paired $t$ test). We also applied serotonin to nine of these cells. Serotonin depressed the spike counts in three cells and facilitated the spike count in one cell. The vehicle alone, however, did not. A representative neuron is shown in Figure 1 and illustrates that although the cell's spike counts were depressed by serotonin, the vehicle solution alone caused no change in spike count. We are therefore confident that whatever changes in responsiveness we observed during the application of serotonin were indeed caused by serotonin and not by the vehicle solution or the spread of current through the ejection electrode.

\section{Serotonin often modulated responses to tone bursts}

Serotonin had a substantial effect on the spike counts evoked by tone bursts in 46 of the 70 neurons tested (66\%). Typically, serotonin depressed responses evoked by tone bursts. Of the 46 cells whose responses to tone bursts were changed by serotonin, 36 cells $(78 \%)$ had spike counts that were depressed. Although our criterion for depression was a spike-count reduction of $30 \%$, the depression was commonly greater, where the average spike counts were depressed to $66.8 \%( \pm 4 \%)$ of their pre-ejection values. The depressive effects of serotonin are illustrated by the neuron in Figure 2.

Figure 2 also illustrates four other features that were seen in the majority of IC cells whose tone-evoked discharges were affected by serotonin. The first feature is that serotonin depressed

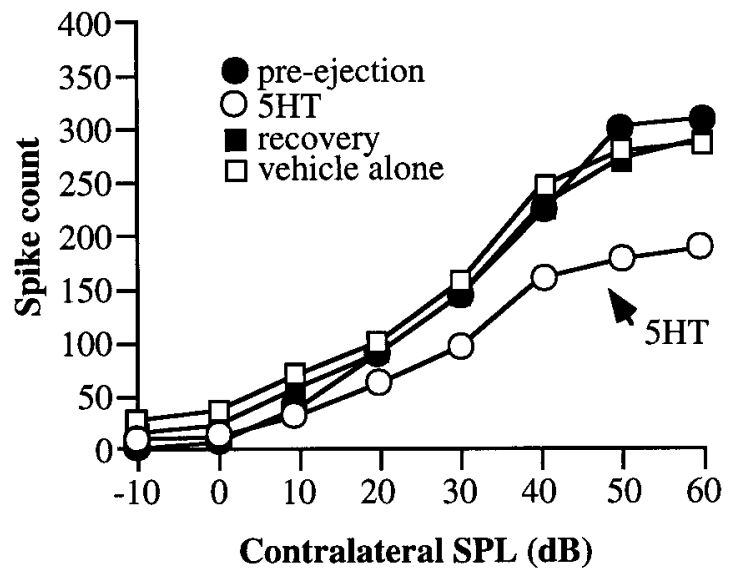

Figure 1. Neuron in which iontophoresis of 5-HT depressed tone-evoked discharges whereas iontophoresis of vehicle solution alone had no effect on neuronal responsiveness. Controls are spike counts evoked by 20 repetitions of the tone bursts presented over a range of intensities (filled circles). After the controls, serotonin was applied with an ejection current of $50 \mathrm{nA}$ (open circles), which reduced the spike counts evoked by most intensities. After the ejection current was turned off, the spike counts recovered within $5 \mathrm{~min}$ to pre-ejection values (filled squares). After recovery, the vehicle solution alone was iontophoresed with an ejection current of $50 \mathrm{nA}$ (open squares), the same ejection used for iontophoresis of serotonin. The spike counts evoked during the ejection of the vehicle solution were virtually the same as those evoked in the preejection condition. BF was $34.1 \mathrm{kHz}$. The tone-burst duration was 20 msec. SPL, Sound pressure level.

the spike counts by approximately the same proportion at every sound intensity. In this neuron the spike counts were depressed $\sim 50 \%$ below the pre-ejection spike count at each intensity. Consequently, the shape of the rate-level function was not changed by serotonin, because it was monotonic before and during the application of serotonin. In other cells, the rate-level function was nonmonotonic both before and during the application of serotonin. The second common feature of Figure 2 was that the toneevoked temporal discharge pattern was not markedly changed by serotonin. If a neuron displayed a sustained or an onset discharge pattern in the pre-ejection condition, serotonin simply reduced the overall magnitude of the response. This was also generally true for neurons whose tone-evoked responses were facilitated by serotonin, as described below. The third common feature was that the spike counts recovered within 5 min after terminating the application of serotonin. Although not every cell recovered completely, 70 neurons for which we obtained data $5 \mathrm{~min}$ after the termination of serotonin application recovered to an average of $>90 \%$ of their pre-ejection spike counts (recovery was obtained from 24 neurons tested with tones and from 36 neurons tested with FM sweeps). The fourth feature was that the threshold of tone-evoked discharges was usually not changed by serotonin; thresholds for tone bursts were unchanged in $67 \%$ of the neurons recorded. In the other $33 \%$ of neurons, for which serotonin did change the threshold, the direction of the threshold change always corresponded to the change in the spike count. For example, when serotonin depressed spike counts, it also caused a threshold increase in those cells.

The effects of serotonin on the neuron represented in Figure 2 also had some features not shared by the general neuronal population in the inferior colliculus. One feature was that the spikecount depression for the neuron in Figure 2 was accompanied by a statistically significant decrease in first-spike latency at low 

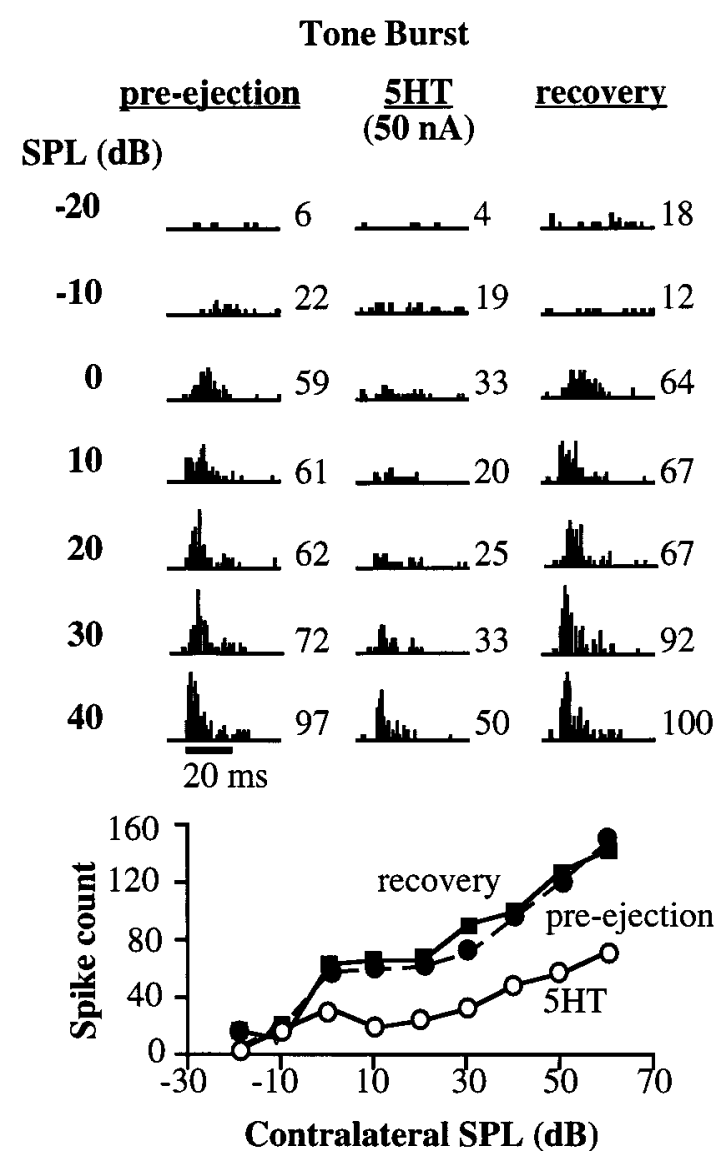

Figure 2. Neuron in which serotonin depressed tone-evoked discharges. Top, PST histograms from 20 tone presentations of BF tone bursts at various intensities. Spike counts evoked by each intensity are shown to the right of each histogram. Responses evoked before application of serotonin (pre-ejection), during application of 5-HT, and 5 min after serotonin was terminated (recovery) are shown in the three panels. Bottom, The spike counts evoked by increasing sound intensities for the three conditions. Open circles show spike counts obtained during application of serotonin, closed circles represent spike counts in the pre-ejection condition, and closed squares show spike counts in the recovery condition. The BF was 44 $\mathrm{kHz}$. The tone-burst duration was $20 \mathrm{msec}$, indicated by the time bar.

intensities. As shown in Figure $3 A$, the pre-ejection latency at 10 $\mathrm{dB}$ SPL was $9.9 \mathrm{msec}$ and increased to $16.2 \mathrm{msec}$ during the application of serotonin. Serotonin-induced latency changes, however, were not generally seen in inferior colliculus neurons. Indeed, when we pooled the latencies of the population we recorded, there were no significant differences in average firstspike latencies to tone bursts, as shown in Figure $3 B$, or to standardized FM sweeps (Fig. 3C) at any intensity.

In contrast to the depression seen in most neurons, serotonin facilitated tone-evoked responses in only 10 of the 46 cells (22\%). The facilitation in these 10 cells, however, was usually substantial and caused the spike count to increase on average by $168.7 \%$ $( \pm 61.4 \%)$. Facilitation is illustrated by the neuron in Figure 4 . This neuron showed a particularly dramatic facilitation, partly because it hardly fired at all to tones before serotonin was applied (in the pre-ejection condition). Other neurons had relatively high pre-ejection spike counts that were also facilitated by at least $30 \%$, and usually more, by serotonin. Although it is not obvious in Figure 4, the facilitation in most neurons was typically an increase in discharge vigor without a marked change in discharge pattern.
A.

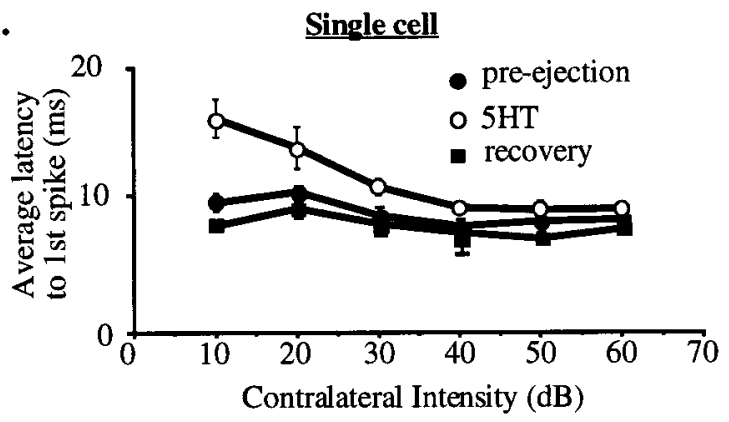

B.

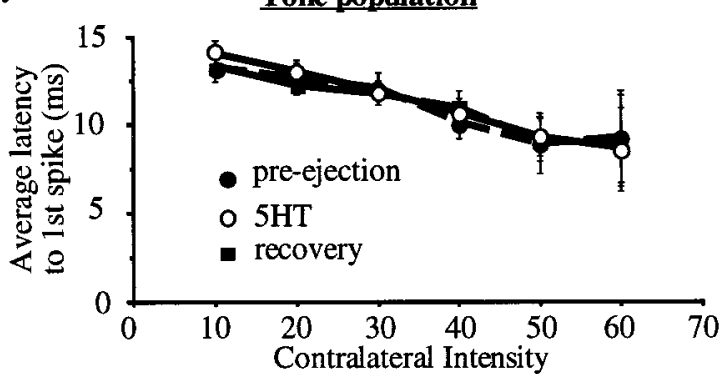

( $\mathrm{dB}$ above threshold)

C.

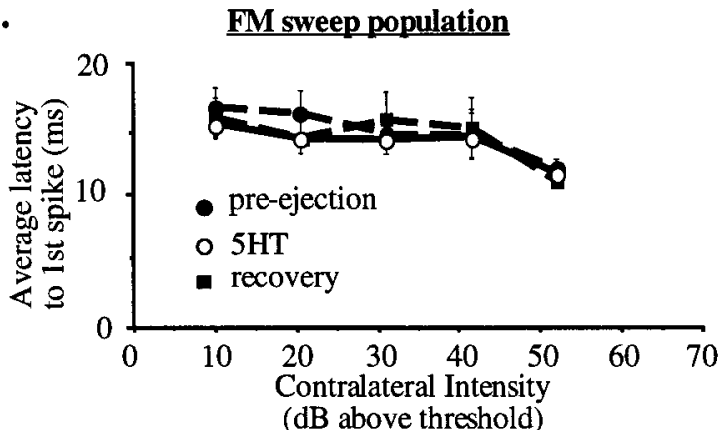

Figure 3. Serotonin effects on latency to first spike. $A$, Single neuron in which serotonin changed the latency to the first spike is shown. Latency values are taken from the neuron in Figure 2; each data point represents the average latency for 20 tone presentations at the sound level shown on the $x$-axis. The average latency during serotonin application is significantly different from the average pre-ejection latency (ANOVA, $p<$ $0.01)$. $B$, Average tone-evoked latency of the population of IC cells was not significantly changed by serotonin at any sound intensity (2-tailed paired $t$ tests, $p>0.1$ ). Sample sizes were, at $10 \mathrm{~dB}$ above threshold, 46; at $20 \mathrm{~dB}, 46$; at $30 \mathrm{~dB}, 39$; at $40 \mathrm{~dB}, 27$; at $50 \mathrm{~dB}, 11$; and, at $60 \mathrm{~dB}, 4$. C, Serotonin had no overall effect on latencies to FM sweeps across the population of inferior colliculus neurons at any sound intensity (2-tailed paired $t$ tests, $p>0.1$ ). Sample sizes were, at $10 \mathrm{~dB}$ above threshold, 29; at $20 \mathrm{~dB}, 29$; at $30 \mathrm{~dB}, 24$; at $40 \mathrm{~dB}, 15$; and, at $50 \mathrm{~dB}, 3$. Error bars represent the SEM.

Thus, the overall response magnitude of sustained cells increased while the discharges of onset cells became more vigorous at the onset of the signal without prolonged discharges that would transform the pattern into a sustained pattern. Two exceptions were the neurons (see Figs. 7, 8) whose discharge patterns were lengthened by serotonin.

In summary, in the 46 cells whose responsiveness to tone bursts was modulated by serotonin, the spike counts in the majority $(78 \%)$ of the cells were depressed, whereas the spike counts in only a minority of the population $(22 \%)$ were facilitated. 


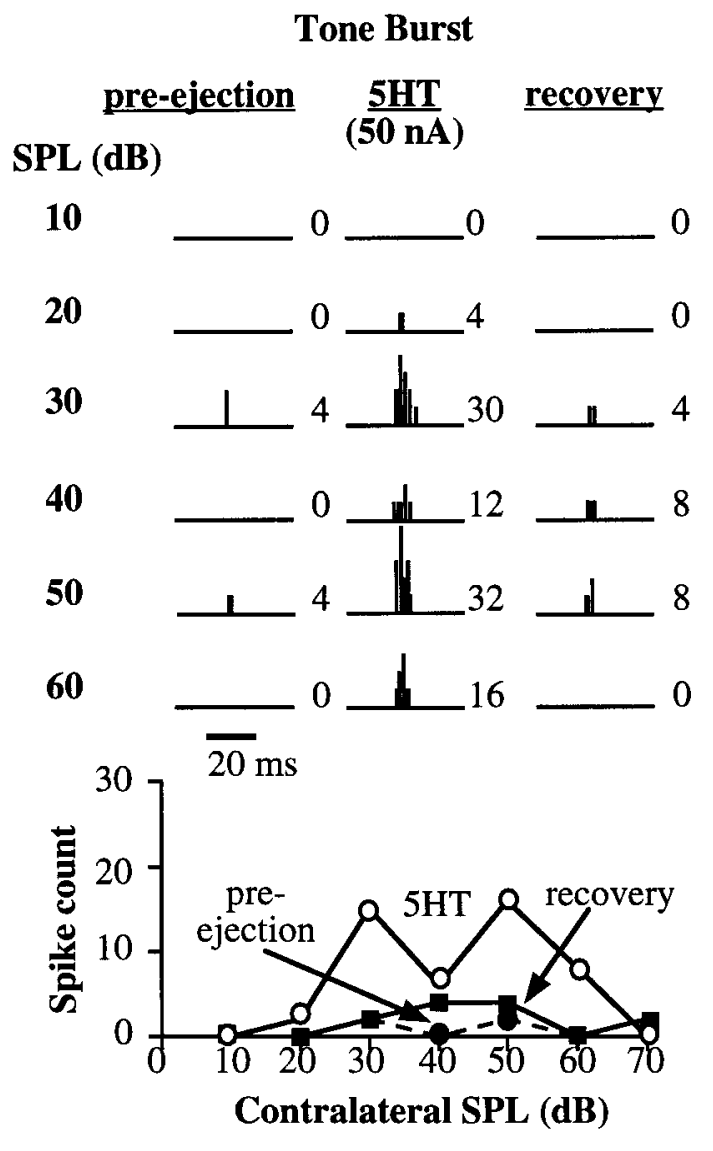

Figure 4. Serotonin facilitated tone-evoked discharges. Figure conventions are described in Figure 2. The BF was $23.5 \mathrm{kHz}$. The tone-burst duration was $20 \mathrm{msec}$, indicated by the time bar.

\section{Serotonin also altered spontaneous activity in some cells}

Serotonin altered spontaneous activity as well as tone-evoked activity in many IC neurons. To evaluate the degree to which serotonin had parallel effects on spontaneous and tone-evoked activity, we collected data on spontaneous activity in 38 neurons in which we also evaluated the effect of serotonin on tone-evoked responses. Because the spontaneous firing rate of IC neurons in these animals is low, we collected spike counts in the absence of acoustic stimulation in a $200 \mathrm{msec}$ window (in contrast to the 20-50 msec window for tone-evoked discharges) and summed the discharges in up to 50 trials. Serotonin depressed spontaneous activity in 16 cells (42\%), facilitated spontaneous activity in 12 cells $(32 \%)$, and had no effect on 10 others (26\%). Serotonin also affected the tone-evoked responses in 21 of these 38 neurons, depressing $15(39 \%)$ and facilitating $6(16 \%)$.

The effects of serotonin on spontaneous and tone-evoked discharges were not always the same. In the 38 neurons tested, the effect (or lack of effect) of serotonin on spontaneous and toneevoked activity was qualitatively similar in 18 neurons and different in 20 other neurons. Figure 5, $A$ and $B$, illustrates neurons for which serotonin had similar effects on both spontaneous and tone-evoked discharges, either to decrease (Fig. $5 A$ ) or to increase (Fig. $5 B$ ) discharges. Figure 5, $C$ and $D$, illustrates neurons for which serotonin had different effects on spontaneous and tone-evoked activity. For the neuron in Figure $5 C$, serotonin increased spontaneous discharges while it suppressed tone-
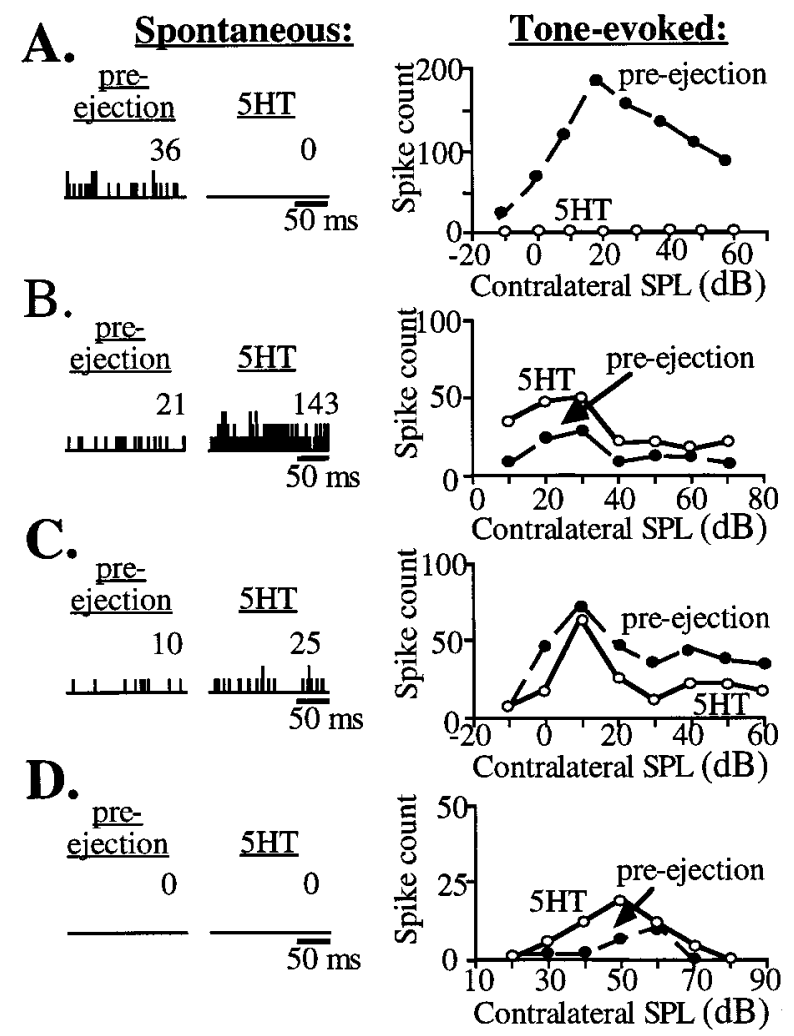

Figure 5. Effects of 5-HT on spontaneous and tone-evoked activity in four cells. Left-hand records, PST histograms show spontaneous activity before (pre-ejection) and during application of serotonin. These records are the accumulated spike counts over a $200 \mathrm{msec}$ time period for 50 trials for the neuron in $A$ and 20 trials for the neurons in $B-D$. The number to the upper right of each histogram is the total spike count during this period. Right-hand records, Rate-level functions of tone-evoked activity before (pre-ejection) and during application of serotonin are shown. $A, B$, Two neurons in which serotonin had the same effect on spontaneous and tone-evoked activity are shown. $A$, Serotonin decreased both spontaneous and tone-evoked activity. $B$, Serotonin increased spontaneous and toneevoked activity and decreased the threshold for the tone-evoked response. $C, D$, Two neurons in which serotonin had different effects on spontaneous and tone-evoked activity are shown. $C$, Serotonin increased spontaneous activity but decreased tone-evoked activity. $D$, Serotonin had no effect on spontaneous activity but increased tone-evoked activity. The BFs of the cells in $A-D$ were $27,25.7,25.5$, and $26.8 \mathrm{kHz}$, respectively.

evoked discharges. For the neuron in Figure $5 D$, serotonin had no effect on the spontaneous activity but facilitated tone-evoked activity.

These effects of serotonin on tone-evoked and spontaneous activity may provide insights into whether serotonin was acting pre- or postsynaptically. Serotonin can act by altering one or more conductances that either hyperpolarize or depolarize the postsynaptic cell (Andrade and Nicoll, 1987; Colino and Halliwell, 1987; Baskys et al., 1989), or it can act presynaptically by altering a conductance in presynaptic regions, thereby influencing transmitter release (Segal, 1990; Mintz and Korn, 1991; Huang et al., 1993). If serotonin were acting only on postsynaptic receptors in IC neurons, it should have the same effect on both spontaneous and tone-evoked activity, as it did in some IC neurons. The fact that serotonin had different effects on spontaneous and toneevoked activity in approximately one-half of the other cells suggests that the effects of serotonin on IC neurons were not exclusively postsynaptic. 


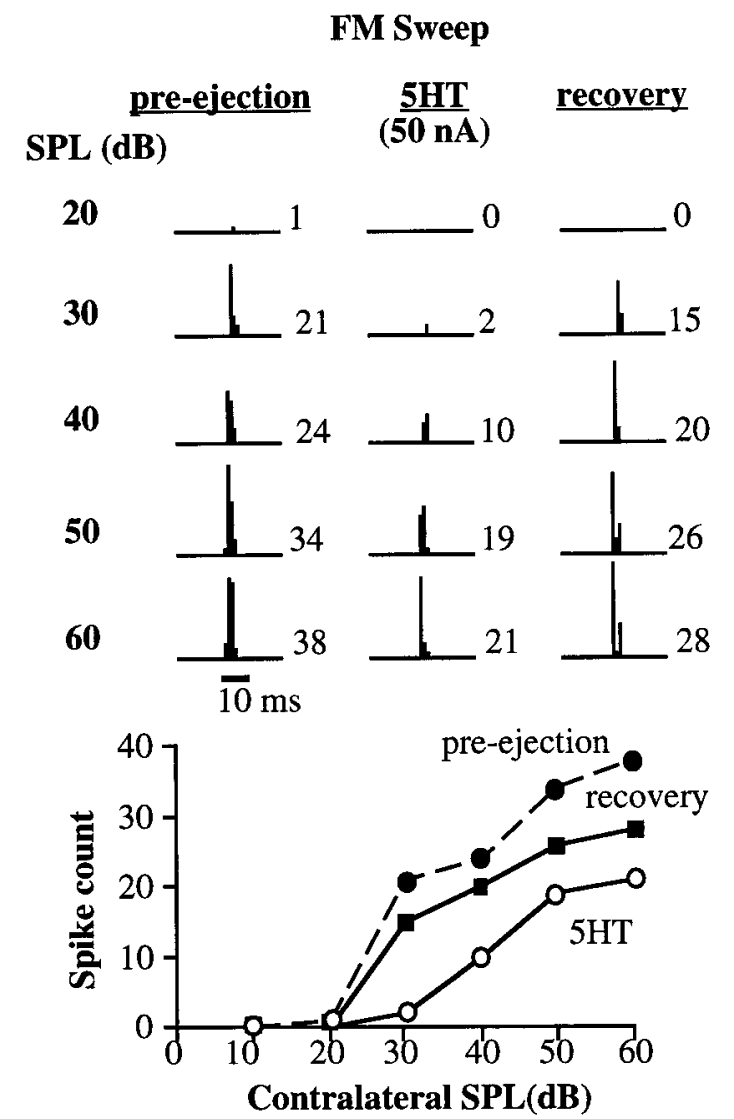

Figure 6. Serotonin depressed FM-evoked discharges. Figure conventions are described in Figure 2. The neuron's BF was $24.8 \mathrm{kHz}$. The FM signal swept from 29.8 to $19.8 \mathrm{kHz}$ and was $10 \mathrm{msec}$ in duration, as indicated by the time bar.

\section{Serotonin effects on responses to standardized FM sweeps were evenly mixed between facilitation and depression}

Forty-five neurons were tested with standardized FM sweeps. The responses of 20 cells (44\%) were influenced by serotonin, but the effects of serotonin on these 20 cells were more evenly divided between depression (12 cells; 60\%) and facilitation ( 8 cells; 40\%) than were the effects of serotonin on tone-evoked responses described above. Serotonin depressed the spike counts of the 12 cells $(60 \%)$ by an average of $59.9 \%( \pm 5.2 \%)$ of their pre-ejection spike counts.

Figure 6 illustrates the depressive effects of serotonin on FMevoked activity. For this neuron, serotonin caused an overall depression of spike counts. Although the depression was greatest at lower intensities (30-40 dB SPL), there was no change in the general shape of the rate-level function, which was monotonic before and during the application of serotonin. In this neuron, serotonin also caused an increase in threshold and a small, but significant, increase in the latency to the first spike. For example, at $60 \mathrm{~dB}$ the average latency to the first spike changed from 13.2 msec before serotonin to $13.9 \mathrm{msec}$ during serotonin addition.

Overall, serotonin had a larger effect on FM-evoked thresholds than on tone-evoked thresholds. With FM sweeps, serotonin changed thresholds in $44 \%$ of the neurons, whereas tone-evoked thresholds were changed in $33 \%$ of the neurons. As was the case for tone-evoked threshold changes, when serotonin changed

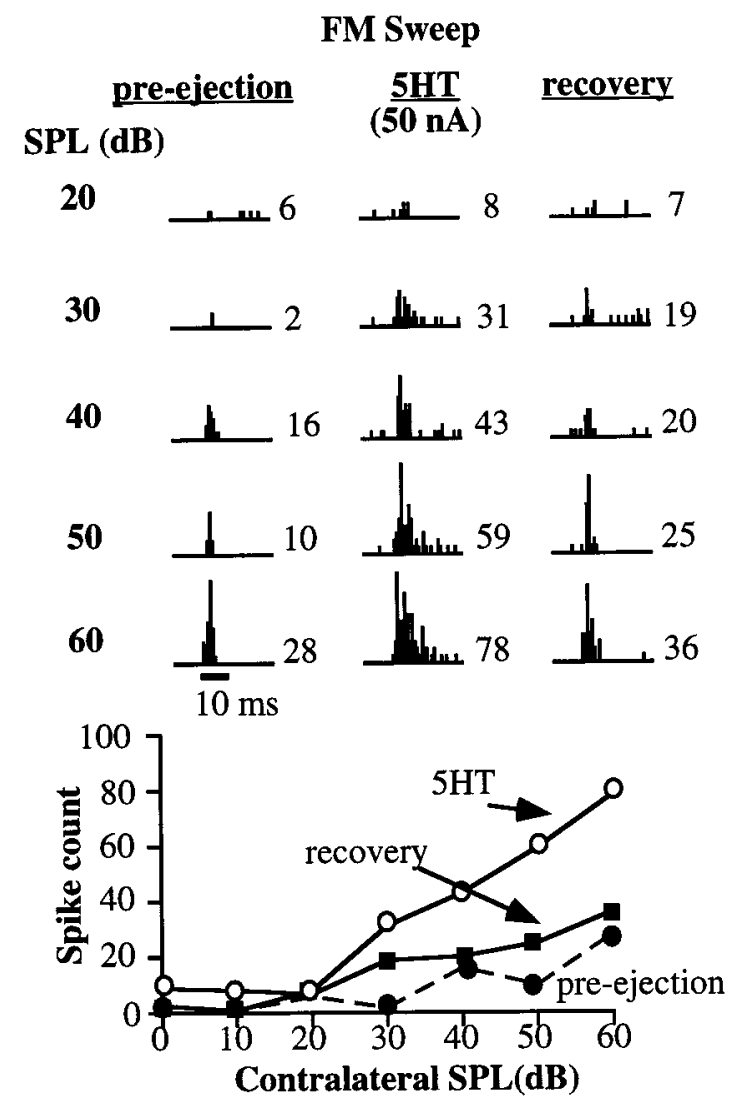

Figure 7. Serotonin facilitated FM-evoked discharges. Figure conventions are described in Figure 2. The neuron's BF was $18 \mathrm{kHz}$. The FM signal swept from 23 to $13 \mathrm{kHz}$ and was $10 \mathrm{msec}$ in duration, as indicated by the time bar. This neuron was one in which serotonin increased the duration of the discharge train.

the FM-evoked threshold, the direction of the threshold change always corresponded to the change in the spike count, in that when serotonin raised the threshold it always depressed spike counts and when it lowered the threshold it always facilitated responses.

In 8 of the 20 cells $(40 \%)$, serotonin facilitated spike counts evoked by FM sweeps by an average of $144 \%( \pm 45 \%)$. Figure 7 illustrates facilitation in a neuron in which FM-evoked spike counts more than doubled at most sound intensities. This serotonin-induced facilitation was attributable both to an increase in the magnitude of the initial discharge rate and to an increase in the duration of the discharge train. For example, at $50 \mathrm{~dB}$ SPL, the initial discharge rate to the FM sweep was far more vigorous with serotonin, and the duration of the spike train was three times longer than that of the pre-ejection discharge train. Both the duration of the spike train and the spike count partially recovered after serotonin iontophoresis was terminated. Such a serotonininduced change in the temporal discharge pattern was rarely seen with tone-evoked facilitation, although it was seen with FM sweeps in another neuron (Fig. 8) besides the neuron in Figure 7. However, in the 6 other neurons in which serotonin facilitated spike counts, the facilitation was not accompanied by a change in the duration of their spike trains, which is similar to the serotonin-induced effects on responses to tone bursts described previously. 


\section{Tone Burst

$\underset{\text { ejection }}{\text { pre- }} \quad \underline{\mathbf{5 H T}} \quad$ recovery

\begin{abstract}
FM Sweep
recovery
\end{abstract}

$\underset{\text { ejection }}{\text { pre- }} \quad \underset{(\mathbf{9 0} \mathrm{nA})}{\mathbf{5 H T}}$

SPL (dB)

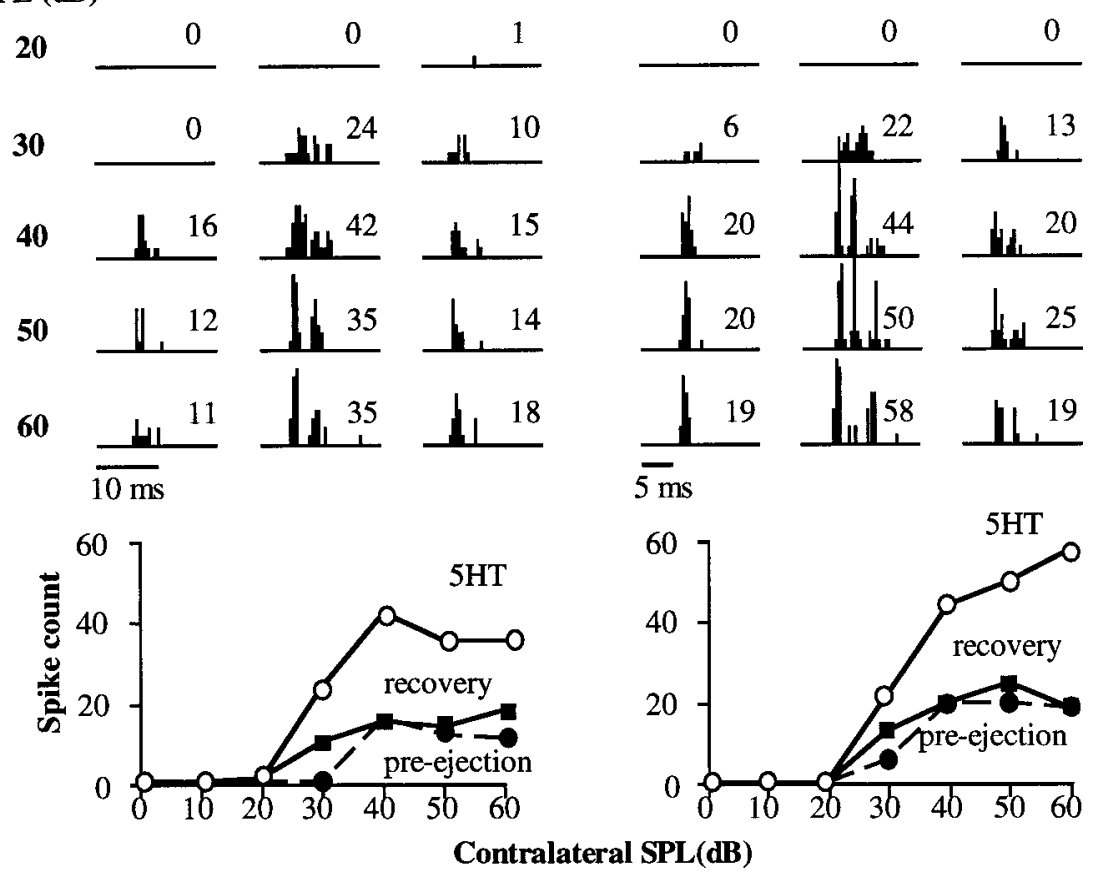

3 


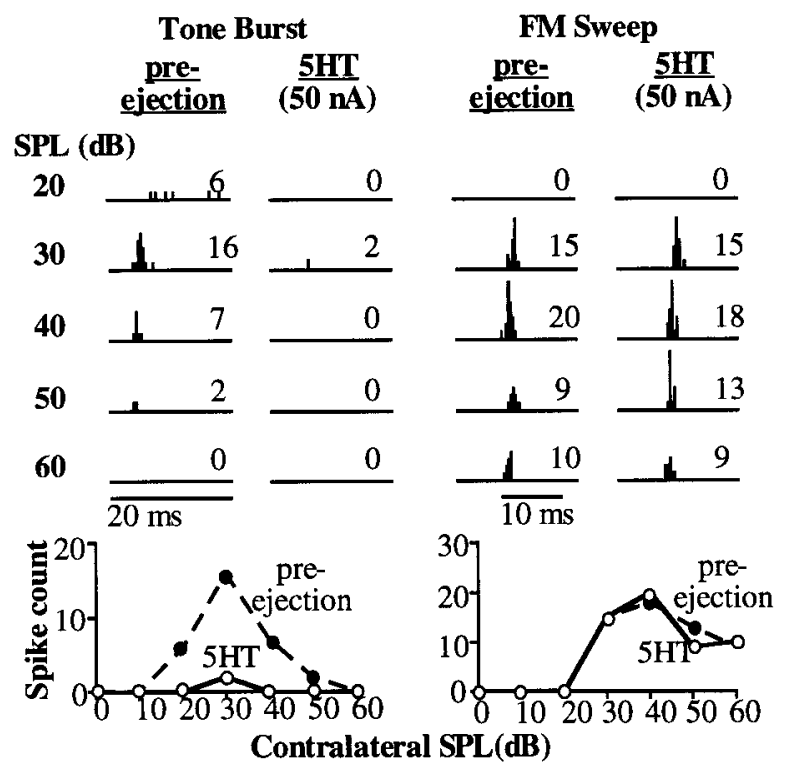

Figure 9. Neuron in which serotonin had a different effect on tone- and FM-evoked responses. Serotonin almost completely suppressed responses to BF tone bursts (left) but had virtually no effect on responses to FM sweeps (right). Figure conventions are described in Figure 2. The neuron's BF was $26 \mathrm{kHz}$. The FM signal swept from 31 to $21 \mathrm{kHz}$. The duration of the tone burst was $20 \mathrm{msec}$, and the duration of the FM sweep was 10 msec, as indicated by the time bars.

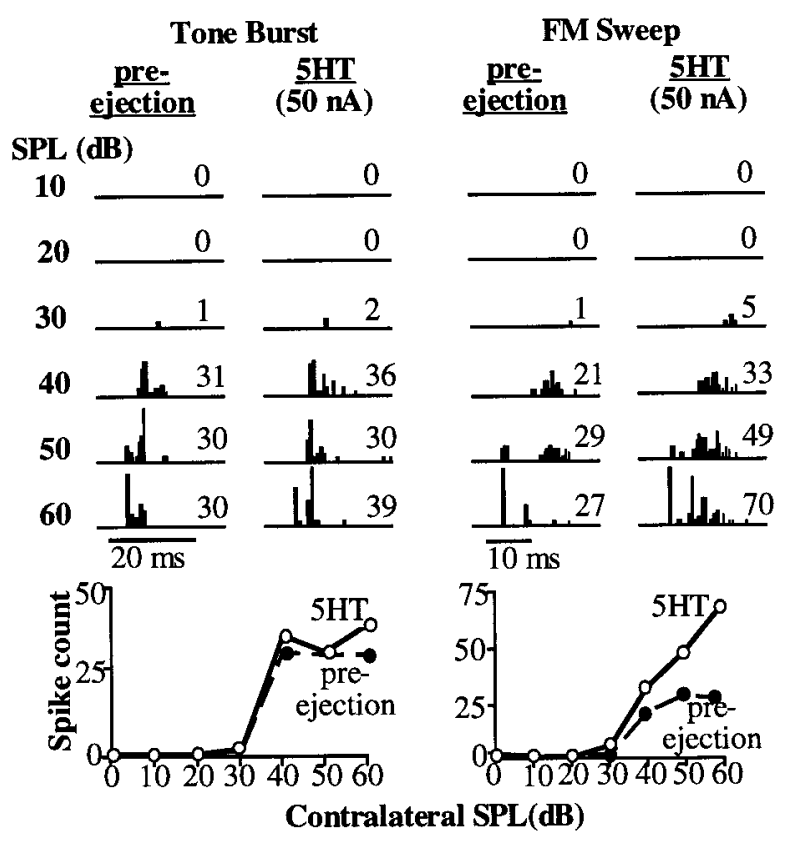

Figure 10. Neuron in which serotonin had a different effect on tone- and FM-evoked responses. For this neuron, serotonin had virtually no effect on responses to BF tone bursts (left) but facilitated the responses to FM sweeps (right). Figure conventions are described in Figure 2. The neuron's $\mathrm{BF}$ was $43.5 \mathrm{kHz}$. The FM signal swept from 50 to $40 \mathrm{kHz}$. The duration of the tone burst was $20 \mathrm{msec}$, and the duration of the FM sweep was 10 msec, as indicated by the time bars.

influence the responses evoked by FM sweeps that had different temporal or spectral structures. Differential serotonin effects on FM sweeps were seen in $15.5 \%$ (11 of 71) of the neurons to which we presented two or more types of FM sweeps. The neurons shown in Figures 11 and 12 illustrate these effects. For the neuron

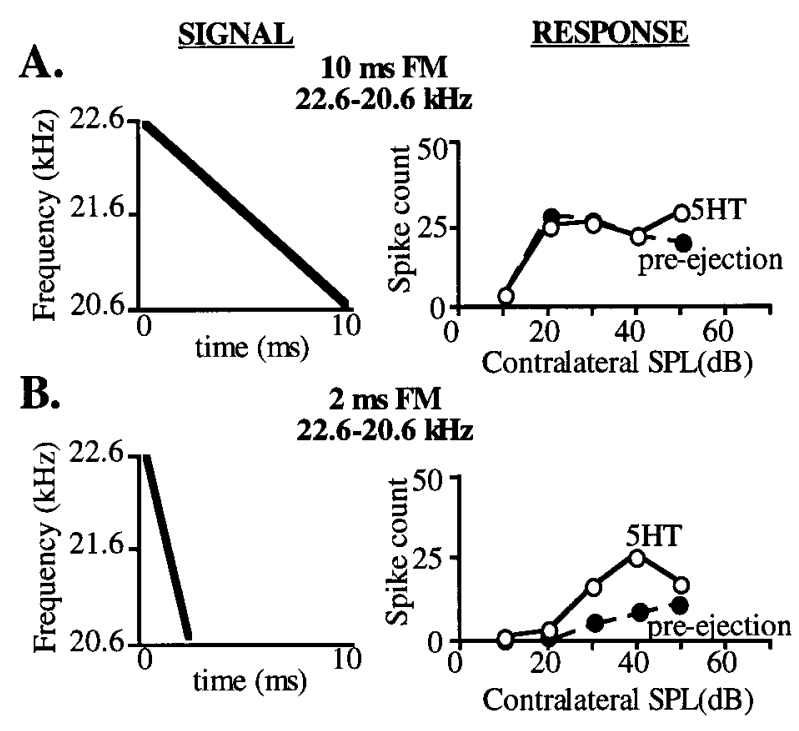

Figure 11. Serotonin can affect the responses to FM sweeps of different structure differently. The neuron's BF was $21.6 \mathrm{kHz}$. $A$, Serotonin had little effect on the response to one type of FM sweep. Left, An FM sweep is plotted as a function of frequency versus time; this FM sweep ranged downward from 22.6 to $20.6 \mathrm{kHz}$ over $10 \mathrm{msec}$. Right, The cell's response to this FM sweep in the pre-ejection and serotonin conditions is plotted as rate-level functions. $B$, Serotonin facilitated the response to one type of FM sweep. Left, The sweep is plotted as a function of frequency versus time; this sweep ranged downward from 22.6 to $20.6 \mathrm{kHz}$ over 2 msec. Right, The rate-level functions for the response to this FM sweep are plotted.

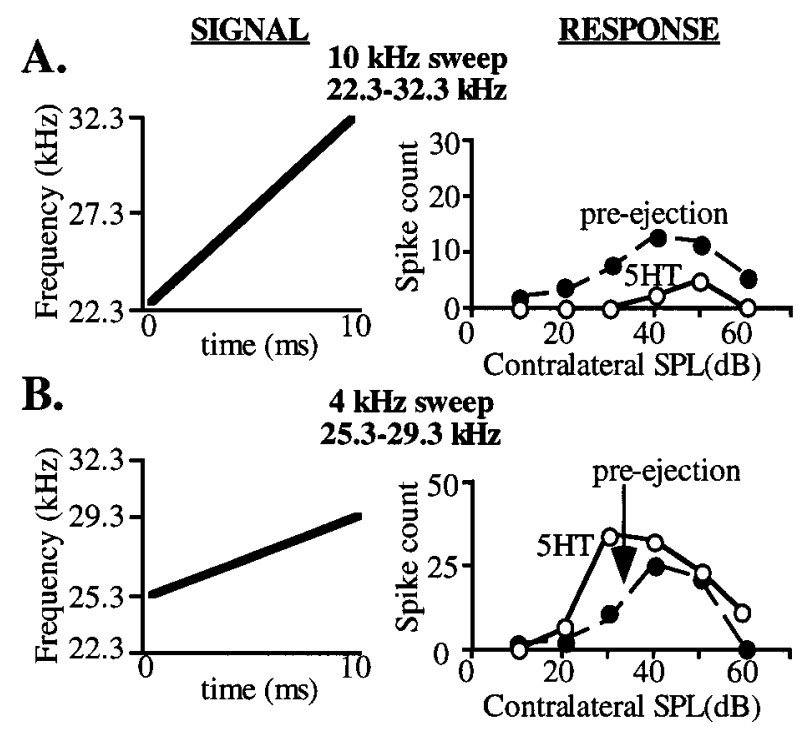

Figure 12. Serotonin can affect the responses to FM sweeps of different structure differently. The neuron's BF was $27.3 \mathrm{kHz}$. A, Serotonin depressed the response to one type of FM sweep. Left, An FM sweep is plotted as a function of frequency versus time; this FM sweep ranged upward from 22.3 to $32.3 \mathrm{kHz}$ over $10 \mathrm{msec}$. Right, The cell's response to this FM sweep in the pre-ejection and serotonin conditions is plotted as rate-level functions. $B$, Serotonin facilitated the response to one type of FM sweep. Left, The sweep is plotted as a function of frequency versus time; this sweep ranged upward from 25.3 to $29.3 \mathrm{kHz}$ over $10 \mathrm{msec}$. Right, The rate-level functions for the response to this FM sweep are plotted.

in Figure 11, we presented two FM signals that swept through the same frequencies but had different durations and, thus, different sweep rates. Both signals swept downward from 22.6 to $20.6 \mathrm{kHz}$, but one signal swept through these frequencies over a $10 \mathrm{msec}$ 
duration whereas the other signal sweep through the same frequencies over $2 \mathrm{msec}$. When the $10 \mathrm{msec}$ FM sweeps were presented, the neuron fired briskly, and spike counts increased monotonically with increasing signal intensities. Serotonin had little effect on the discharge magnitude at any intensity, except at $50 \mathrm{~dB}$ SPL at which the spike count increased slightly over the pre-ejection level. In contrast, the responses evoked by the $2 \mathrm{msec}$ FM sweep were initially weak and were markedly facilitated by serotonin.

Figure 12 shows a neuron in which serotonin had differential effects on FM sweeps that had the same duration but different frequency excursions. The duration of both FM sweeps was 10 msec, but one signal swept upward by $10 \mathrm{kHz}$, from 22.3 to 32.3 $\mathrm{kHz}$, whereas the other signal swept upward by $4 \mathrm{kHz}$, from 25.3 to $29.3 \mathrm{kHz}$. Serotonin depressed responses to the $10 \mathrm{kHz}$ sweep at all intensities. In contrast, serotonin enhanced responses at most intensities to the shallower, $4 \mathrm{kHz}$ sweep. Thus, in this neuron serotonin had a different effect on responses to FM sweeps that had the same duration but differed in frequency excursion, whereas in the previous neuron serotonin differentially influenced responses to FM sweeps that swept through the same range of frequencies but with different sweep rates.

\section{DISCUSSION}

There are two central findings of this paper. The first is that serotonin depresses or facilitates the responsiveness of many IC neurons. In this regard, our findings agree with three previous reports that serotonin can have either facilitative or depressive effects on auditory neurons (Faingold et al., 1991; Ebert and Ostwald, 1992; Wang and Robertson, 1997). The second and more interesting finding is that the effect of serotonergic modulation on the responses of many IC neurons is dependent on the type of auditory signal presented. Thus the predominant effect of serotonin on responses evoked by tone bursts is depression, whereas serotonin depresses or facilitates the responses evoked by FM sweeps in approximately equal numbers of neurons. More strikingly, this difference in the effects of serotonin on responses to tones and FM sweeps also occurs in single IC neurons. Thus serotonin often had no effect on the responses evoked by one signal, whereas in the same cell it had a profound effect on the responses evoked by another signal. Finally, in some neurons serotonin has a differential influence on responses to FM sweeps that have different temporal or spectral structures. These differential effects of serotonin have not been reported previously.

\section{Mechanism of serotonin effects is complex}

Ideally, we would like to explain the effects of serotonin on IC cells in terms of the particular 5-HT receptors that are activated by serotonergic inputs to IC cells. However, very little is known about the types of 5-HT receptors that are present in the IC, and the techniques that we used provide insufficient information for advancing explanations on this level. There is a vast array of 5-HT receptors in the CNS that can act pre- or postsynaptically. Seven serotonin receptor families, designated $5-\mathrm{HT}_{1}$ through $5-\mathrm{HT}_{7}$, have been classified, and numerous subtypes are recognized within each family (Peroutka, 1994). With one exception, the $5-\mathrm{HT}_{3}$ receptor (Gyermek, 1995), all other receptors act metabotropically, by triggering second messenger cascades that ultimately modulate one or more currents (Andrade et al., 1986; Peroutka, 1994). The variety of currents modulated by one or another of the 5-HT receptors is impressive and includes sodium currents and a variety of potassium and calcium currents, as well as a mixed cation current, the $I_{h}$ current (Colino and Halliwell, 1987; Berger and Takahashi, 1990; McCormick and Pape, 1990; Sah, 1990; Bayliss et al., 1995; Aghajanian and Marek, 1997). However, the only 5-HT receptor in the auditory system identified so far is the $5-\mathrm{HT}_{1 \mathrm{~A}}$ receptor, which is densely distributed in the IC (Thompson et al., 1994). This is the only receptor that has been identified so far because probes for other 5-HT receptors have not been used in studies of the auditory system.

Although we cannot explain our results via the influences of various receptor types, our results suggest that serotonin modulates some of the excitatory and/or inhibitory synapses but not others. Stated differently, it would appear that serotonin facilitates (or depresses) the responses to frequencies that generate portions of the cell's excitatory tuning curve as well as facilitating or depressing the responses to frequencies that generate its inhibitory flanks. For example, one possibility is that serotonin depresses excitation evoked by BF tone bursts in some neurons and also depresses the inhibition evoked by higher or lower frequencies that comprise the cell's inhibitory surround. If we assume that the starting frequencies of the sweep initially stimulate the inhibitory surround, which would be depressed by serotonin, and then sweep through the excitatory portions of its tuning curve, the elimination of inhibition could offset the depression of excitation. This arrangement offers a potential explanation for how serotonin could depress the responses to BF tone bursts while having little or no apparent effect on responses to FM sweeps. The effects of serotonin on excitatory tuning and its inhibitory flanks and the degree to which those influences can explain facilitation or depression of responses evoked by various signals are currently under investigation and will be the subject of a future report.

Although the mechanisms are not well understood, the serotonergic influences that we observed have functional consequences of considerable importance. Below we discuss those consequences and argue that the modulatory effects of serotonin can profoundly change the population coding of acoustic signals in the IC. We then discuss why the modulation is highly dynamic and may well be subject to behavioral states.

\section{Some functional consequences of serotonergic innervation on the processing of acoustic information in the IC}

The finding that serotonin often modulates responses to tones differently than responses evoked by FM sweeps shows that the conclusions drawn from studies evaluating the effects of serotonin in auditory nuclei would be determined, in large part, by the nature of the acoustic signal used. If, for example, we had only evaluated the influence of serotonin on responses evoked by tone bursts, we would have concluded that the dominant effect of serotonin on IC neurons is depression. However, had we only evaluated the influence of serotonin on FM sweeps, we would have concluded that serotonin effects are mixed equally between facilitation and depression. Both conclusions would be justified by the data, but neither is entirely correct. Rather the particular effect that serotonin has on a neuron most often depends on the nature of the acoustic signal, as illustrated both by the differential effects serotonin often has on responses to tones compared with FM sweeps and also by the differential influences serotonin can have on responses to FM sweeps that differ in temporal or spectral structure. It therefore follows that serotonin modulates the population coding differently for different signals.

We point out that the results of this study also may not accu- 
rately reflect the way serotonin modulates responses evoked by the various signals these animals normally receive. Although many of the FM sweeps that we used are structurally similar to the echolocation calls emitted by Mexican free-tailed bats, they are not the same as their natural echolocation calls. The majority of FM signals that we used had durations of 5-10 msec, swept downward only by $10 \mathrm{kHz}$, and most importantly were spectrally tailored so that they swept through the neuron's BF. The natural echolocation calls have larger frequency excursions, which sweep from $\sim 40$ to $20 \mathrm{kHz}$ over a 2-5 msec duration, are emitted with a harmonic, and change systematically both in duration and spectral content as these bats search for, detect, and then home in on a target (Simmons et al., 1978, 1979). Additionally, these animals use a rich diversity of acoustic signals for communication. Calls emitted during interactions between mothers and infants, for example, are rich in harmonics, have both upward and downward frequency modulations, and have durations of tens of milliseconds (Gelfand and McCracken, 1986; Balcombe and McCracken, 1992). Because the effect of serotonin in many neurons depends on the type of signal presented, it seems likely that if we had used a repertoire of true echolocation and communication signals we would have obtained a more complex set of serotonin effects in an even larger proportion of cells than we found with the more limited stimuli that we presented in this study.

\section{Serotonergic modulation is dynamic and influenced by behavioral states}

The substantial impact of serotonin on the responsiveness of many IC neurons suggests that modulation of the activity of serotonergic neurons should also modulate responsiveness of neurons at each level of the auditory pathway. Below we discuss this issue as well as what some of the functional consequences of having response properties of auditory neurons modulated by serotonergic innervation might be.

With regard to the issue of the activity of serotonergic neurons, previous studies have shown that some serotonergic neurons in the dorsal raphe, the region that provides the largest projection to the IC, have a slow rhythmic discharge rate in quiet, awake animals (Trulson and Jacobs, 1979; Trulson and Trulson, 1982; Rasmussen et al., 1986). This basal level of activity presumably has some influence on the processing of acoustic information in awake animals. The hypothesis that basal serotonergic activity influences auditory processing is consistent with a recent study that showed that systemic depletion of serotonin, by intravenous injections of para-chlorophenylalanine, significantly increased the latency of auditory brainstem responses from several lower levels in awake bush babies (Revelis et al., 1998). Taken together, these findings suggest that basal levels of endogenous serotonin influence the responsiveness of auditory neurons in passively listening awake animals. It also follows that the effects of the iontophoretically applied serotonin we observed most likely enhanced the effects of endogenous serotonin.

The roles of the serotonergic system become more interesting when changes in its activity levels induced by behavioral states, such as when an animal vocalizes or directs its attention to a sound source, are considered. A recent proposal by Fornal et al. (1996) is particularly relevant to this issue. On the basis of studies showing that serotonin depresses responses in visual and nociceptive systems, they suggest that under conditions in which the animal is not directing attention to any stimulus, the basal activity of serotonergic neurons inhibits afferent sensory systems and thereby depresses activity in sensory systems. However, their studies have also shown that when an animal orients to a novel stimulus, the activity of dorsal raphe neurons decreases significantly. Thus, they propose that the decreased serotonergic activity disinhibits sensory systems. The disinhibition allows the sensory system to respond with facilitated responses as the animal focuses its attention on the stimulus that evoked the orienting response.

The results of this study, however, are inconsistent with the hypothesis of a general suppression of sensory responsiveness because of serotonergic activity. If we had presented only tone bursts, the dominant effect of serotonin would have been a suppression that is consistent with the hypothesis. However, the increased number of neurons in which responses to FM sweeps are facilitated and the differential effects serotonin has on responsiveness evoked by tones and FM sweeps in individual neurons are not consistent with the proposition that serotonin simply has a suppressive effect on auditory neurons.

Rather, our results show that the modulatory influences that serotonin exerts differ among neurons and often depend on the nature of the acoustic signal. Whatever form these serotonininduced shifts in responsiveness assume, they result in changes in the population coding of an auditory stimulus. These shifts in responsiveness can be viewed as a functional reconfiguration of the neural circuitry, with serotonin accentuating responses to sounds in some neurons and dampening it in others. Additionally, the efficacy of the serotonergic innervation depends on the activity level of the raphe serotonergic system, which itself is partially modulated by sensory stimuli and by attention or other behavioral states. All of this suggests that the pattern of activity presented to the IC from lower centers, as well as the way the IC population responds to that innervation, can be changed substantially when an animal emits vocalizations, when it directs attention toward a stimulus, and by its general state of arousal. In short, our data suggest that the sound-evoked population activity in the IC is not simply a consequence of the hard-wiring that connects the IC to lower and higher regions but rather is highly dynamic because of the functional reconfigurations induced by serotonin and almost certainly other neuromodulators as well.

\section{REFERENCES}

Adams JC (1979) Ascending projections to the inferior colliculus. J Comp Neurol 183:519-538.

Aghajanian GK, Marek GJ (1997) Serotonin induces excitatory postsynaptic potentials in apical dendrites of neocortical pyramidal cells. Neuropharmacology 36:589-599.

Aitkin L (1986) The auditory midbrain: structure and function in the central auditory pathway. Clifton, NJ: Humana.

Andrade R, Nicoll RA (1987) Pharmacologically distinct actions of serotonin on single pyramidal neurones of the rat hippocampus recorded in vitro. J Physiol (Lond) 394:99-124.

Andrade R, Malenka RC, Nicoll RA (1986) A G protein couples serotonin and $\mathrm{GABA}_{\mathrm{B}}$ receptors to the same channels in hippocampus. Science 234:1261-1265.

Balcombe JP, McCracken GF (1992) Vocal recognition in Mexican freetailed bats: do pups recognize mothers? Anim Behav 43:79-87.

Baskys A, Niesen CE, Davies MF, Carlen PL (1989) Modulatory actions of serotonin on ionic conductances of hippocampal dentate granule cells. Neuroscience 29:443-451.

Bassant MH, Ennouri K, Lamour Y (1990) Effects of iontophoretically applied monoamines on somatosensory cortical neurons of unanesthetized rats. Neuroscience 39:431-439. 
Bayliss DA, Umemiya M, Berger AJ (1995) Inhibition of N- and P-type calcium currents and the afterhyperpolarization in rat motoneurones by serotonin. J Physiol (Lond) 485:635-647.

Berger AJ, Takahashi T (1990) Serotonin enhances a low-voltageactivated calcium current in rat spinal cord. J Neurosci 10:1922-1928.

Beyerl BD (1978) Afferent projections to the central nucleus of the inferior colliculus in the rat. Brain Res 145:209-223.

Bodenhamer RD, Pollak GD, Marsh DS (1979) Coding of fine frequency information by echoranging neurons in the inferior colliculus of the Mexican free-tailed bat. Brain Res 171:530-535.

Brugge JF (1992) An overview of central auditory processing. In: The mammalian auditory pathway: neurophysiology (Popper AN, Fay RR, eds), pp 1-35. New York: Springer.

Brunso-Bechtold JK, Thompson GC, Masterton RB (1981) HRP study of the organization of auditory afferents ascending to the central nucleus of inferior colliculus in cat. J Comp Neurol 197:705-722.

Byrne JH, Kandel ER (1996) Presynaptic facilitation revisited: state and time dependence. J Neurosci 16:425-435.

Colino A, Halliwell JV (1987) Differential modulation of three separate K-conductances in hippocampal CA1 neurons by serotonin. Nature 328:73-77.

Ebert U, Ostwald J (1992) Serotonin modulates auditory information processing in the cochlear nucleus of the rat. Neurosci Lett 145:51-54.

Faingold CL, Gehlbach G, Caspary DM (1991) Functional pharmacology of inferior colliculus neurons. In: Neurobiology of hearing: the central auditory system (Altschuler RA, Clopton BM, Bobbin RP, Hoffman DW, eds), pp 223-251. New York: Raven.

Fornal CA, Metzler CW, Marrosu F, Ribiero-do-Valle LE, Jacobs BL (1996) A subgroup of dorsal raphe serotonergic neurons in the cat is strongly activated during oral-buccal movements. Brain Res 716:123-133.

Gelfand DL, McCracken GF (1986) Individual variation in the isolation calls of Mexican free-tailed bat pups (Tadarida brasiliensis mexicana). Anim Behav 34:1078-1086.

Grothe B, Schweizer H, Pollak GD, Schuller G, Rosemann C (1994) Anatomy and projection patterns of the superior olivary complex in the Mexican free-tailed bat, Tadarida brasiliensis mexicana. J Comp Neurol 343:630-646.

Grothe B, Park TJ, Schuller G (1997) Medial superior olive in the free-tailed bat: response to pure tones and amplitude-modulated tones. J Neurophysiol 77:1553-1565.

Gyermek L (1995) 5-HT3 receptors: pharmacologic and therapeutic aspects. J Clin Pharmacol 35:845-855.

Harris-Warrick RM, Nagy F, Nusbaum MP (1992) Neuromodulation of stomatogastric networks by identified neurons and transmitters. In: Dynamic biological networks: the stomatogastric nervous system (Harris-Warrick RM, Marder E, Selverston AI, Moulins M, eds), pp 87-137. Cambridge, MA: MIT.

Havey DC, Caspary DM (1980) A simple technique for constructing "piggy-back" multibarrel microelectrodes. Electroencephalogr Clin Neurophysiol 48:249-251.

Henderson Z, Sherriff FE (1991) Distribution of choline acetyltransferase immunoreactive axons and terminals in the rat and ferret brainstem. J Comp Neurol 314:147-163.

Hsiao C-F, Del Negro CA, Trueblood PR, Chandler SH (1998) Ionic basis for serotonin-induced bistable membrane properties in guinea pig trigeminal motoneurons. J Neurophysiol 79:2847-2856.

Huang X, Mooney RD, Rhoades RW (1993) Effects of serotonin on retinotectal-, corticotectal-, and glutamate-induced activity in the superior colliculus of the hamster. J Neurophysiol 70:723-732.

Huffman RF, Henson Jr OW (1990) The descending auditory pathway and acousticomotor systems: connections with the inferior colliculus. Brain Res Rev 15:295-323.

Irvine DRF (1992) Physiology of the auditory brainstem. In: The mammalian auditory pathway: neurophysiology (Popper AN, Fay RR, eds), pp 153-231. New York: Springer.

Jacobs BL, Azmitia EC (1992) Structure and function of the brain serotonin system. Physiol Rev 72:165-229.

Jankowska E, Läckberg ZS, Dyrehag LE (1994) Effects of monoamines on transmission from Group II muscle afferents in sacral segments in the cat. Eur J Neurosci 6:1058-1061.

Kaiser A, Covey E (1997) 5-HT innervation of the auditory pathway in birds and bats. In: Acoustical signal processing in the central auditory system (Syka JL, ed), pp 71-78. New York: Plenum.

Klepper A, Herbert H (1991) Distribution and origin of noradrenergic and serotonergic fibers in the cochlear nucleus and inferior colliculus of the rat. Brain Res 557:190-201.

Lavdas AA, Blue ME, Lincoln J, Parnavelas JG (1997) Serotonin promotes the differentiation of glutamate neurons in organotypic slice cultures of the developing cerebral cortex. J Neurosci 17:7872-7880.

McCormick DA, Pape H-C (1990) Noradrenergic and serotonergic modulation of a hyperpolarization-activated cation current in thalamic relay neurones. J Physiol (Lond) 431:319-342.

Mintz I, Korn H (1991) Serotonergic facilitation of quantal release at central inhibitory synapses. J Neurosci 11:3359-3370.

Olazábal UE, Moore JK (1989) Nigrotectal projection to the inferior colliculus: horseradish peroxidase transport and tyrosine hydroxylase immunohistochemical studies in rats, cats, and bats. J Comp Neurol 282:98-118.

Oleskevich S, Lacaille J-C (1992) Reduction of GABAB inhibitory postsynaptic potentials by serotonin via pre- and postsynaptic mechanisms in CA3 pyramidal cells of rat hippocampus in vitro. Synapse 12:173-188.

Oliver DL, Huerta MF (1992) Inferior and superior colliculi. In: The mammalian auditory pathway: neuroanatomy (Webster DB, Popper AN, eds), pp 168-221. New York: Springer.

Park TJ, Grothe B, Pollak GD, Schuller G, Koch U (1996) Neural delays shape selectivity to interaural intensity differences in the lateral superior olive. J Neurosci 16:6554-6566.

Park TJ, Klug A, Oswald JP (1998) A novel circuit in the bat's midbrain recruits neurons into sound localization processing. Naturwissenschaften 85:176-179.

Peroutka SJ (1994) Molecular biology of serotonin (5-HT) receptor. Synapse 18:241-260.

Pollak GD, Marsh DS, Bodenhamer R, Souther A (1977) Characteristics of phasic on neurons in inferior colliculus of unanesthetized bats with observations relating to mechanisms for echo ranging. J Neurophysiol 40:926-942.

Pollak GD, Wenstrup JJ, Fuzessery ZM (1986) Auditory processing in the mustache bat's inferior colliculus. Trends Neurosci 9:556-561.

Rasmussen K, Strecker RE, Jacobs BL (1986) Single unit responses of noradrenergic, serotonergic, and dopaminergic neurons in freely moving cats to simple sensory stimuli. Brain Res 369:336-340.

Revelis J, Thompson AM, Britton BH, Thompson GC (1998) Effects of para-chlorophenylalanine (pCPA) on the bush baby auditory brainstem response. Hear Res 116:119-130.

Rogawski MA, Aghajanian GK (1980) Norepinephrine and serotonin: opposite effects on the activity of lateral geniculate neurons evoked by optic pathway stimulation. Exp Neurol 69:678-694.

Ross LS, Pollak GD, Zook JM (1988) Origin of ascending projections to an isofrequency region of the mustache bat's inferior colliculus. J Comp Neurol 270:488-505.

Roth GL, Aitkin LM, Andersen RA, Merzenich MM (1978) Some features of the spatial organization of the central nucleus of the inferior colliculus of the cat. J Comp Neurol 182:661-680.

Sah DW (1990) Neurotransmitter modulation of calcium current in the rat spinal cord. J Neurosci 10:136-141.

Schuller G, Radtke-Schuller S, Betz M (1986) A stereotaxic method for small animals using experimentally determined reference profiles. J Neurosci Methods 18:339-350.

Segal M (1990) Serotonin attenuates a slow inhibitory postsynaptic potential in rat hippocampal neurons. Neuroscience 36:631-641.

Simmons JA, Lavender WA, Lavender BA, Childs JE, Hulebak K, Rigden MR, Sherman J, Woolman B, O'Farrell MJ (1978) Echolocation by free-tailed bats (Tadarida). J Comp Physiol 125:291-299.

Simmons JA, Fenton MB, O'Farrell MJ (1979) Echolocation and pursuit of prey by bats. Science 203:16-21.

Thompson GC, Thompson AM, Garrett KM, Britton BH (1994) Serotonin and serotonin receptors in the central auditory system. Otolaryngol Head Neck Surg 110:93-102.

Trulson ME, Jacobs BL (1979) Raphe unit activity in freely moving cats: correlation with level of behavioral arousal. Brain Res 163:135-150.

Trulson ME, Trulson VM (1982) Differential effects of phasic auditory and visual stimuli on serotonergic neurons in the nucleus raphe dorsalis and nucleus raphe pallidus in freely moving cats. Neurosci Lett $32: 137-142$

Vater M, Kossl M, Horn AK (1992) GAD- and GABA-immunoreactivity 
in the ascending auditory pathway of horseshoe and mustached bats. J Comp Neurol 325:183-206.

Vitalis T, Cases O, Callebert J, Launay J-M, Price DJ, Seif I, Gaspar P (1998) Effects of monoamine oxidase A inhibition on barrel formation in the mouse somatosensory cortex: determination of a sensitive developmental period. J Comp Neurol 393:169-184.

Wang X, Robertson D (1997) Effects of bioamines and peptides on neurones in the ventral nucleus of trapezoid body and rostral periolivary regions of the rat superior olivary complex: an in vitro investigation. Hear Res 106:20-28.

Wang Y, Ramage AG, Jordan D (1996) Mediation by 5HT3 receptors of an excitatory effect of 5-HT on dorsal vagal preganglionic neurones in anaesthetized rats: an ionophoretic study. $\mathrm{Br} \mathrm{J}$ Pharmacol 118:1697-1704

Willard FH, Ho RH, Martin GF (1984) The neuronal types and the distribution of 5-hydroxytryptamine and enkephalin-like immunoreactive fibers in the dorsal cochlear nucleus of the North American opossum. Brain Res Bull 12:253-266.

Yin T, Kuwada S (1984) Neuronal mechanisms of binaural interaction. In: Dynamic aspects of neocortical function (Edelman GM, Gall WE, Cowan WM, eds), pp 263-313. New York: Wiley.

Zook JM, Casseday JH (1982) Origin of ascending projections to inferior colliculus in the mustache bat, Pteronotus parnelli. J Comp Neurol 207:14-28. 